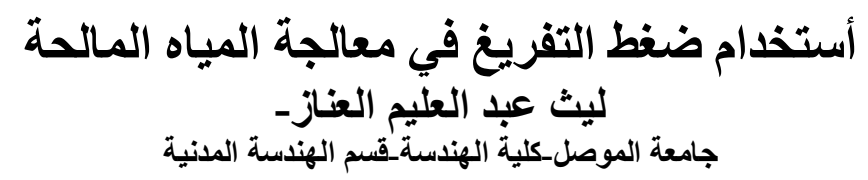

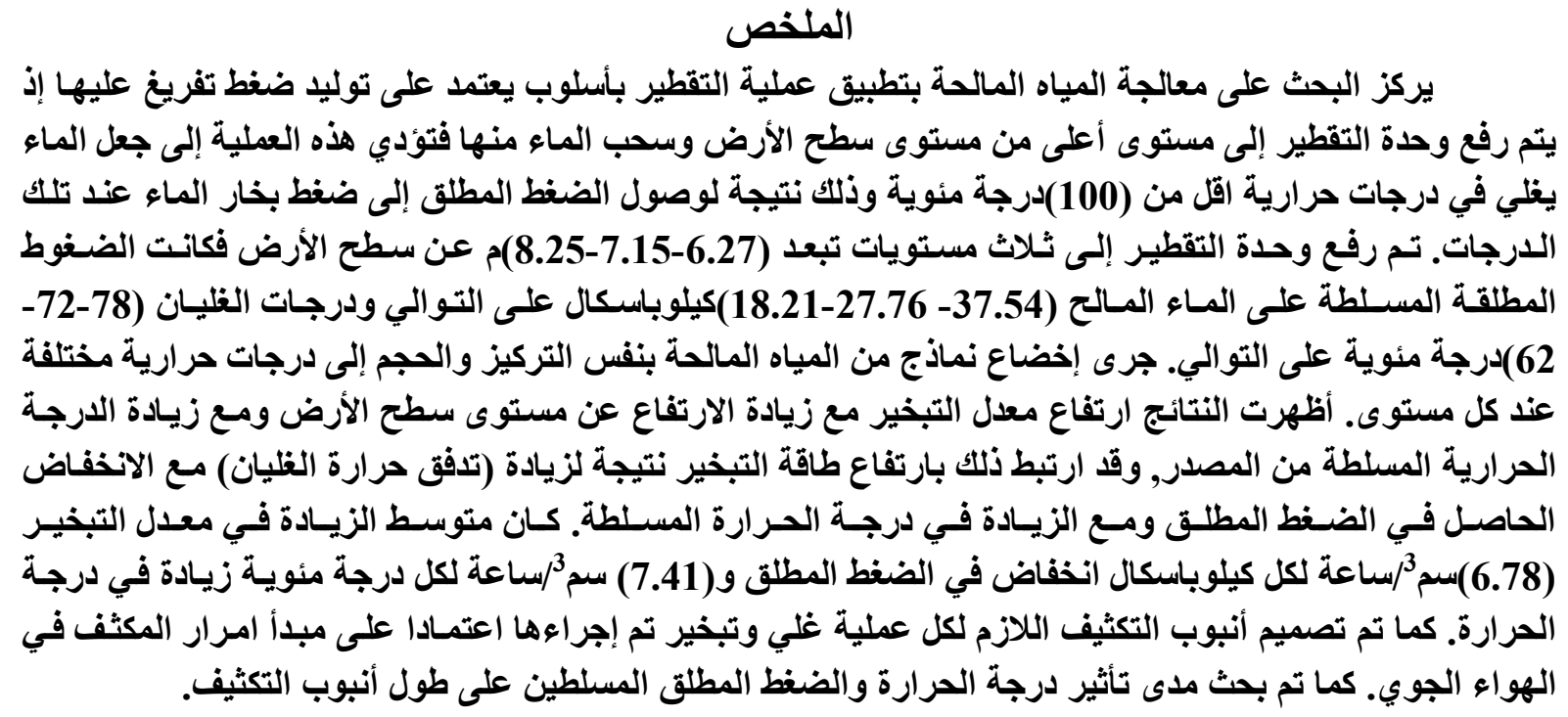

الكلمات الدالة: إزالة الأملاح_التقطير-ضغط التفريغ.

\title{
The Use Of Vacuum Pressure For Water Desalination
}

\author{
Layth Abdul-Aleem Alannaz
}

University of Mosul-College of Engineering

\begin{abstract}
The research focuses on water desalination by distillation process under condition of vacuum pressure. The distillation unit was elevated over the ground surface then water was sucked from it. The water was boiled at temperatures below $(100)^{\circ} \mathrm{C}$ as a result of reaching the absolute pressure to the vapor pressure values of water at these temperatures. The distillation unit was elevated at $(6.27-7.15-8.25) \mathrm{m}$ over ground surface, so that the absolute pressures exerted were $(37.54-27.76-18.21) \mathrm{kPa}$ respectively and the boiling points were (78-72-62) ${ }^{\circ} \mathrm{C}$ respectively. At each elevation of the distillation unit, different values of temperature were applied on the saline water samples (with same concentration and volume). The results indicated increasing in evaporation rate with increased elevation from ground level and with increasing of the applied temperature. This is linked with increasing in evaporation energy as a result of (boiling heat flux) increasing with the depression in absolute pressure and with increasing in temperature. The average increasing in evaporation rate was $(6.78) \mathrm{cm}^{3} / \mathrm{hr}$ for each (kPa) depressing in absolute pressure and $(7.41) \mathrm{cm}^{3} / \mathrm{hr}$ for each $\left({ }^{\circ} \mathrm{C}\right)$ rising in temperature. The condensation tube was designed for each boiling and evaporation process depending on mounting the condenser at atmosphere. The design was affected by the variation in temperature and pressure applied.
\end{abstract}

Key words: Desalination, Distillation, Vacuum pressure

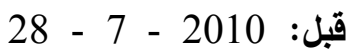

أستلم: 2009 - 9 


\section{المقدمة ومر اجعة المصادر:}

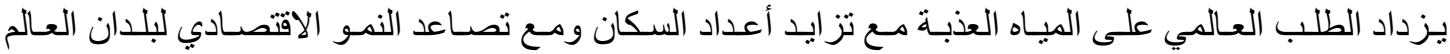

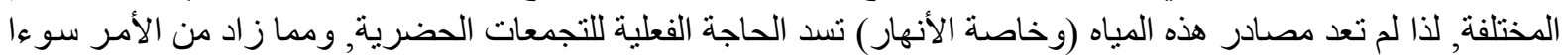

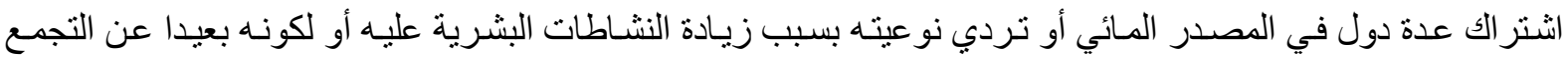

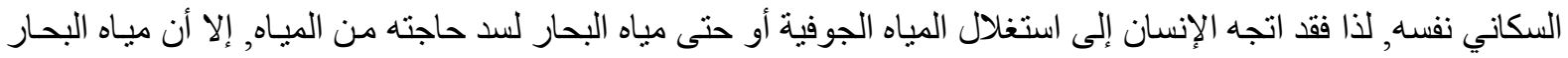

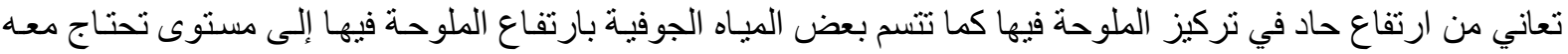

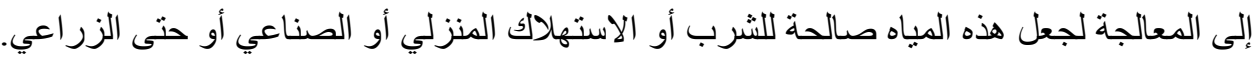

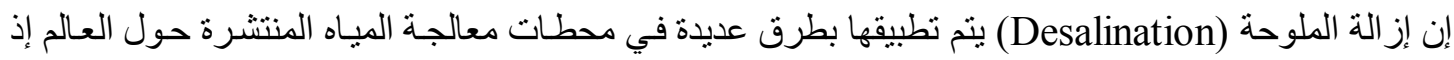
يوجد حاليا أكثر من (12500) محطة إز الذة ملوحة صناعية تعمل بمعدل أنتاج (22.8)مليون متر مكعب باليوم وذللك

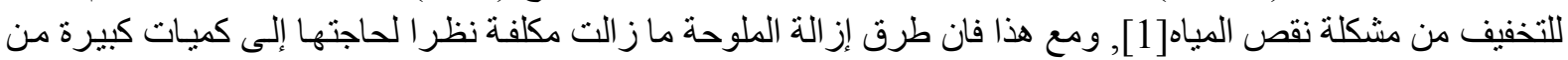

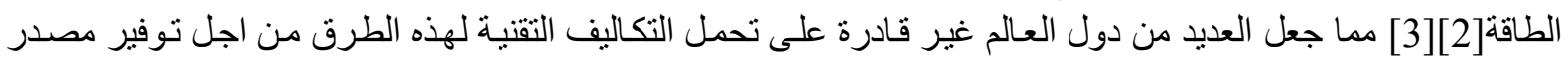

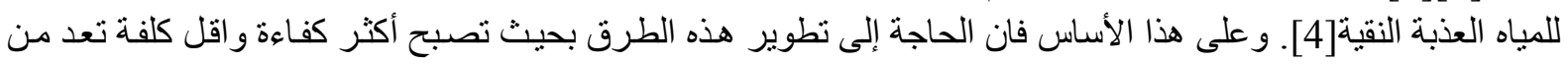

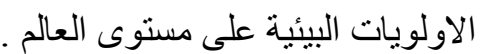
إن الطرق المستخدمة في إزالة الملوحة (Desalination) في محطات معالجة مياه الإسـالة هي التقطير والتنافذ

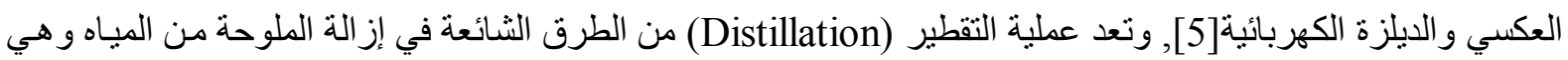

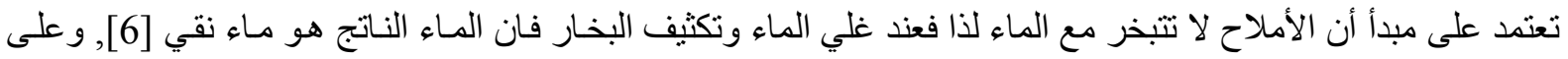

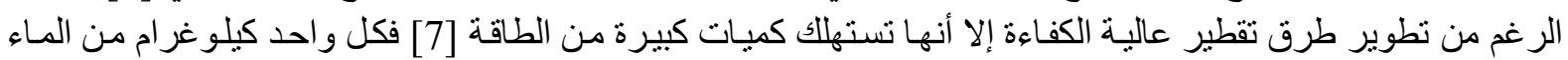

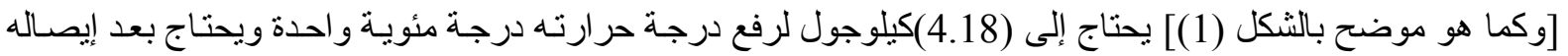

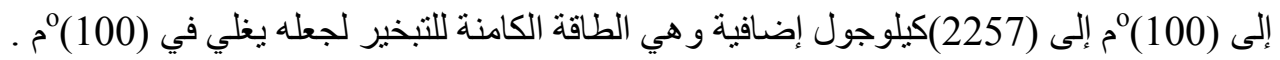

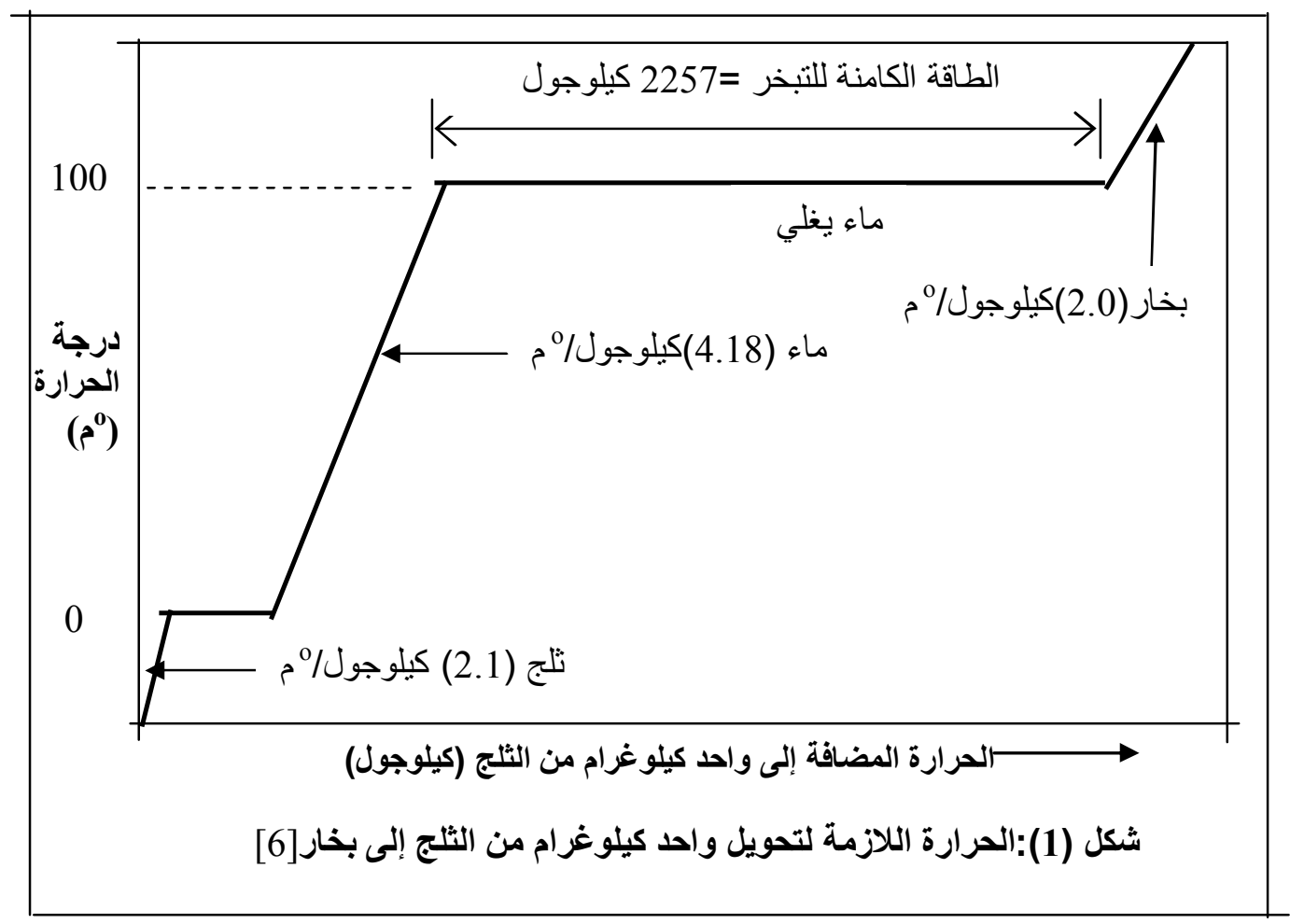

على ضوء ذللك فان جعل الماء يغلي في درجـة حراريـة اقل من (100) مأم سوف يقلل من الطاقة المستهلكة في

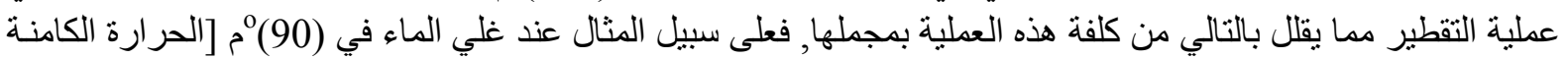

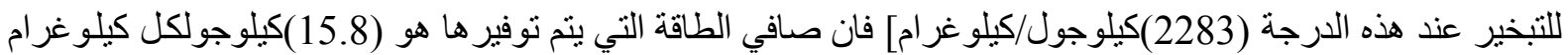


من الماء أي (15800)كيلوجول لكل متر مكعب فالانخفاض في الطاقة المستهلكة يزداد مع الهبوط في درجة غليان المـاء

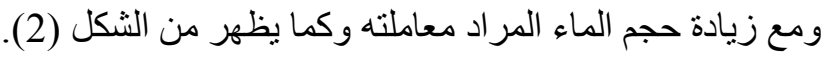

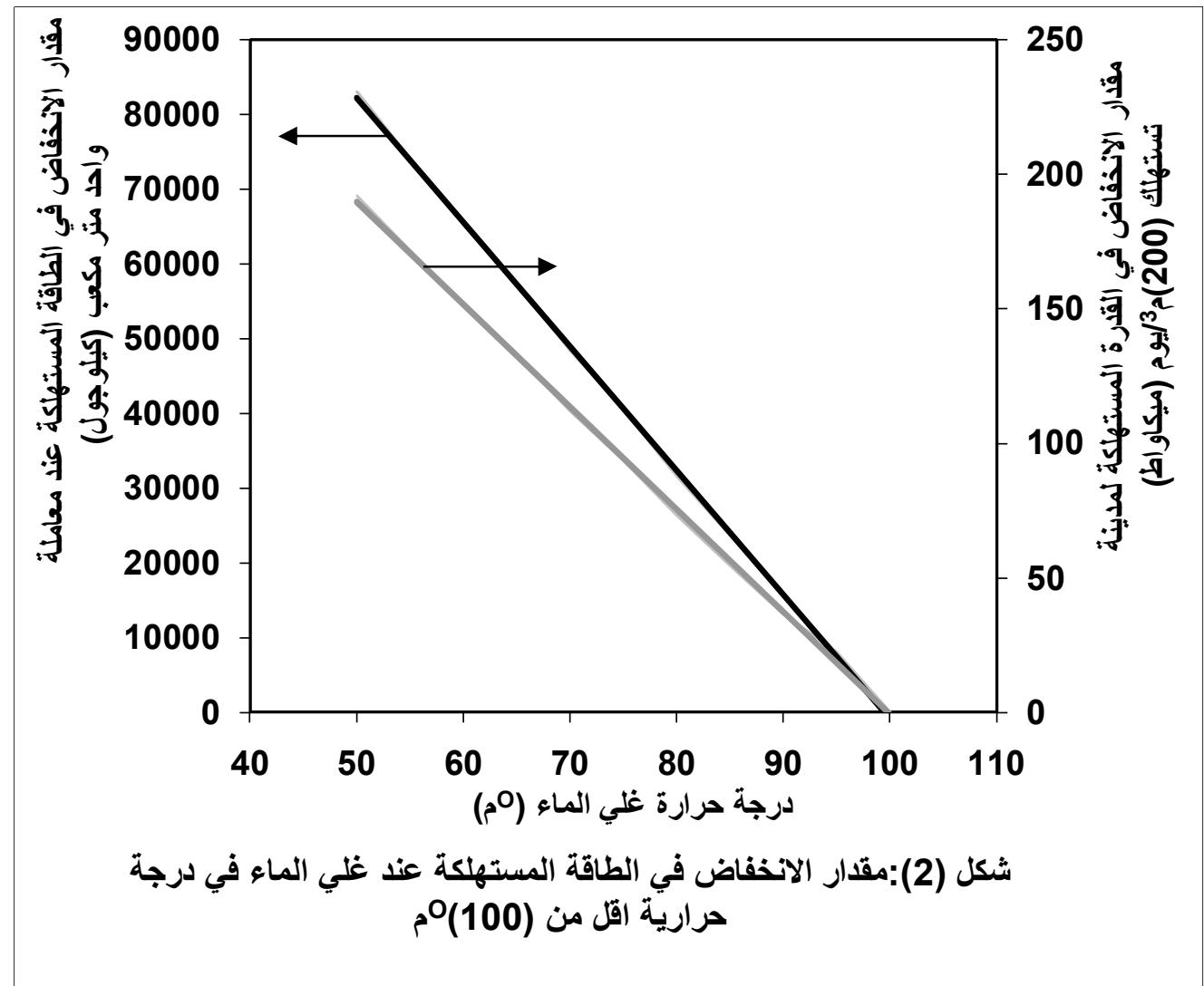

إن نقطة غليان السائل تعتمد على الضغط المسلط و على درجة الحر ارة [8]. فالمـاء كما هو معروف يغلي عند

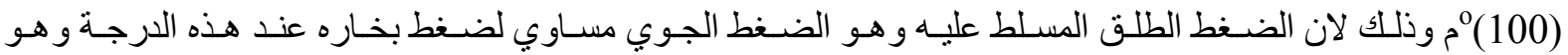

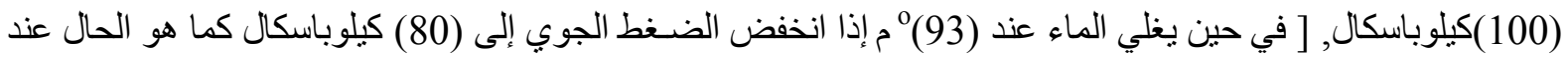

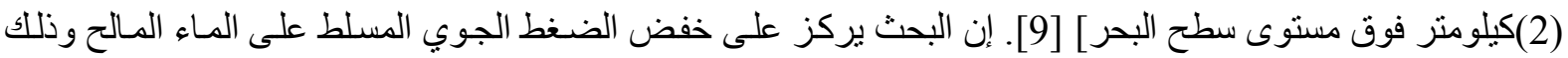

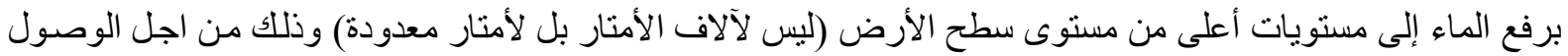

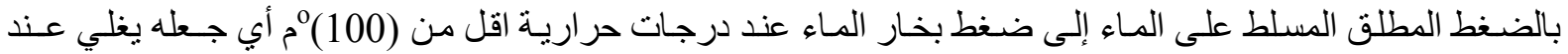

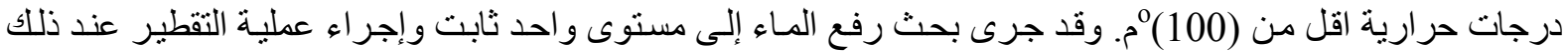

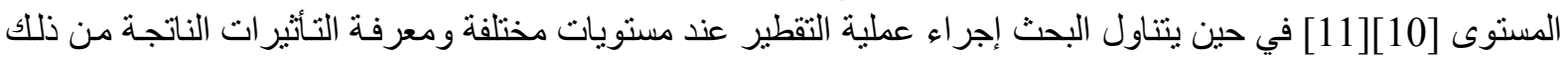

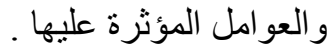

$$
\text { أهداف البحث: }
$$
1-معالجة الماء المالح بعملية تتضمن غليه في درجات حرارية اقل من (100) مأم عن طريق رفعه إلى مستويات أعلى من

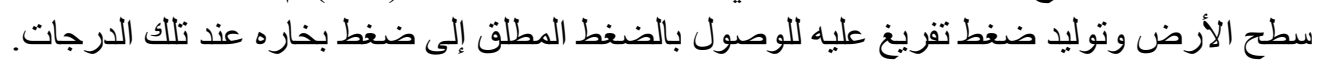
2-بيان مدى نأثر معدل التبخير بتغاير درجة الحرارة عند نفس الضغط المطلق المسلط, وبتغاير الضغط المطلق عند نفس درجة الحرارة. 3-دراسة تأثيثر درجة الحر ارة المسلطة على طاقة التبخير عند الضغوط المطلقة المختلفة. 4-تصميم أنبوب التكثيف اللازم لكل عملية تبخير وتوضيح علاقة ذلك باختلاف درجة الحرارة والضغط الضئ المسلطين. 
تتألف وحدة التقطير وكما هو مبين في الثكل (3) من :

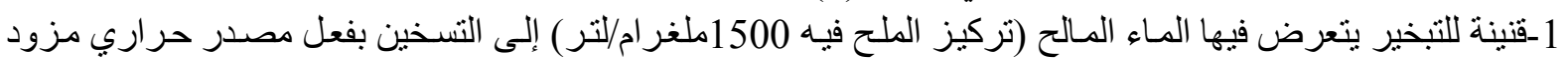

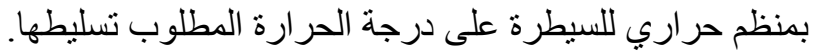

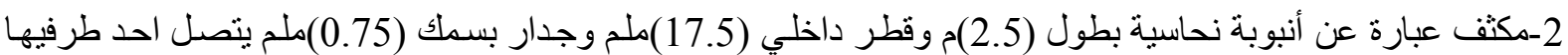

بقتينة التبخير ويتصل طرفه الآخر بقنينة لتجميع الماء المكئف.

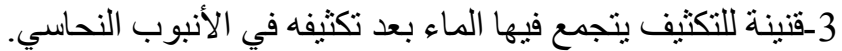
4-أنبوب مطاطي تتصل إحدى نهايتيها بأسفل قنينة التكيف وانيف والنهاية الأخرى بصمام.

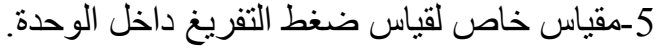

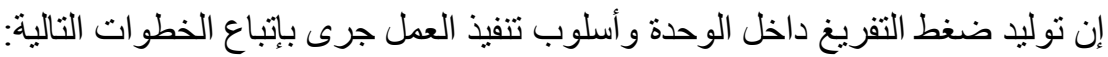

1-رفع وحدة التقطير إلى ارتفاع معين عن سطح الأرض وضل ومد الأنبوب المطاطي المتصل بقتينة النكثيف إلى الأسفل بحيث

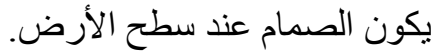
2-ملئ جميع أجزاء الوحدة تقريبا بالماء المر اد معالجته.

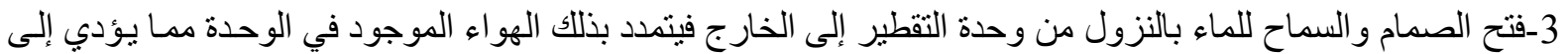

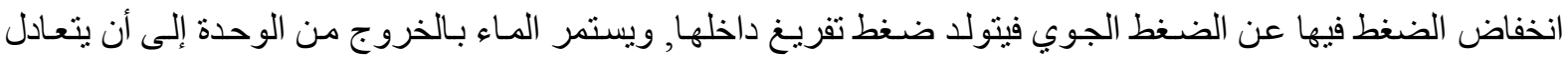

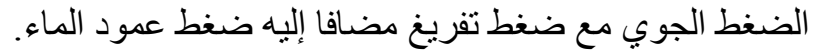
4-تسخين الماء المالح في قتينة التبخير إلى الدرجة الحر ارية المطلوبة ثم يترك الماء يظلي لمدة ساعتين يجري بعدها فتح قإنينة التبخير وحساب معدل التبخير.

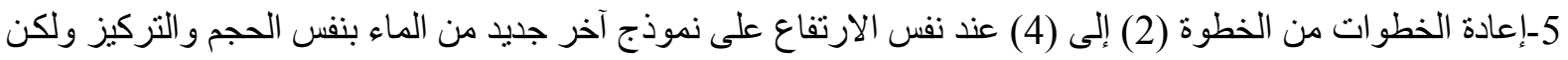

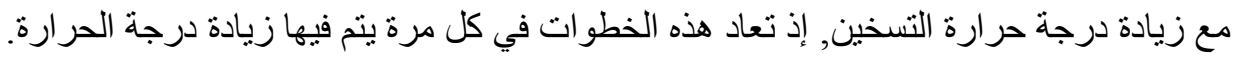
6-رفع وحدة التقطير إلى ارتفاع آخر أعلى من السابق وإعادة الخطوات من (2) إلى (5).

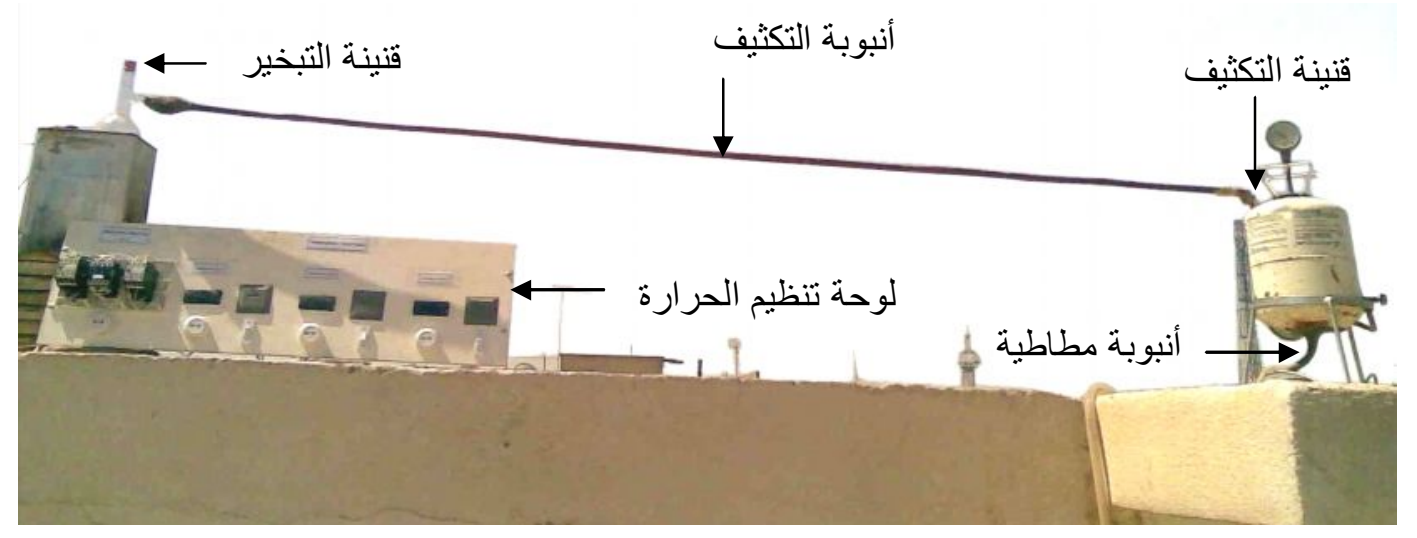

شكل(3): وحدة التقطير المستخدمة في البحث (الارتفاع 8.25م)

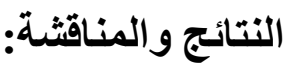

إن رفع وحدة التقطير إلى الأعلى وسحب الماء منها يعود بالفائدة في جانبين أولهما: عدم الحاجة إلى مضخة

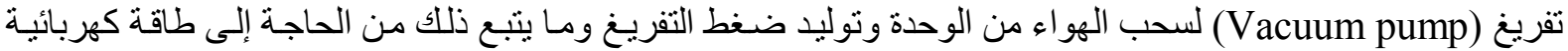

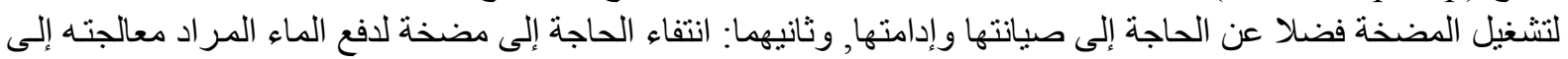

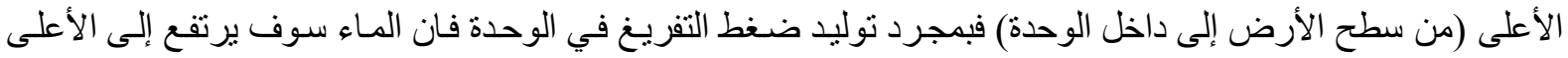


إن الارتفاعات عن سطح الأرض التي جرى رفع وحدة التقطير إليها هي (6.27-7.15-8.25)م وكانت ضنغوط

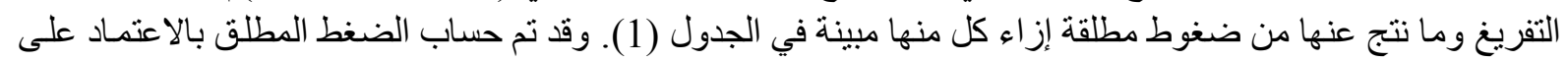

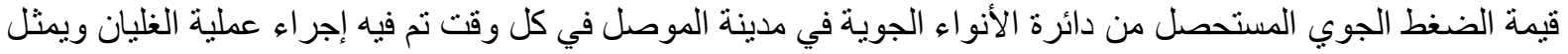

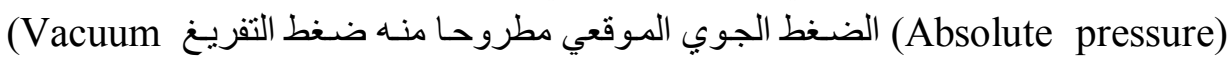
الضغط المطلق

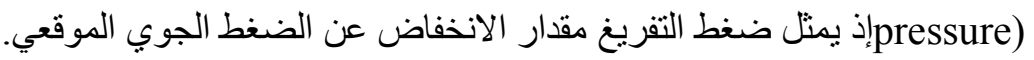

جدول(1): مقدار ارتفاع وحدة التقطير عن سطح الأرض ومقدار كل من ضغط التفريغ والضغط المطلق

\begin{tabular}{|c|c|c|c|}
\hline 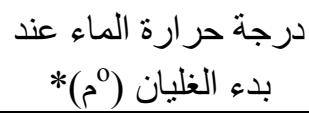 & 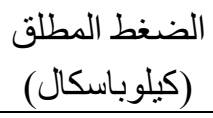 & ضغط التفريغ المتولد & 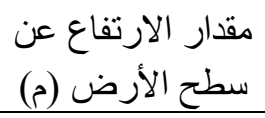 \\
\hline 78 & 37.54 & 61.35 & 6.27 \\
\hline 72 & 27.76 & 71.06 & 7.15 \\
\hline 62 & 18.21 & 80.22 & 8.25 \\
\hline
\end{tabular}

* تبقى درجة الحر ارة التي يبدأ عندها الماء بالغليان ثابتة مهما ازدادت درجة حر ارة المصدر.

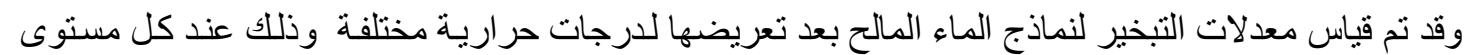

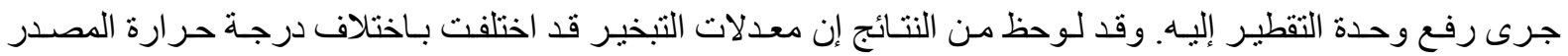
وباختلاف الضغط المطلق المسلط ويظهر ذلك من الثكل (4) إذ يلاحظ زيادة معدلات التبخير مع زيادة درجات التهات الحرارة

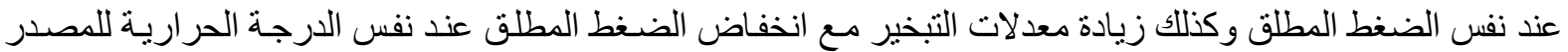

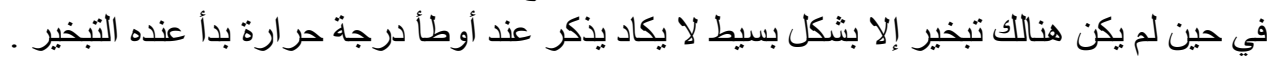

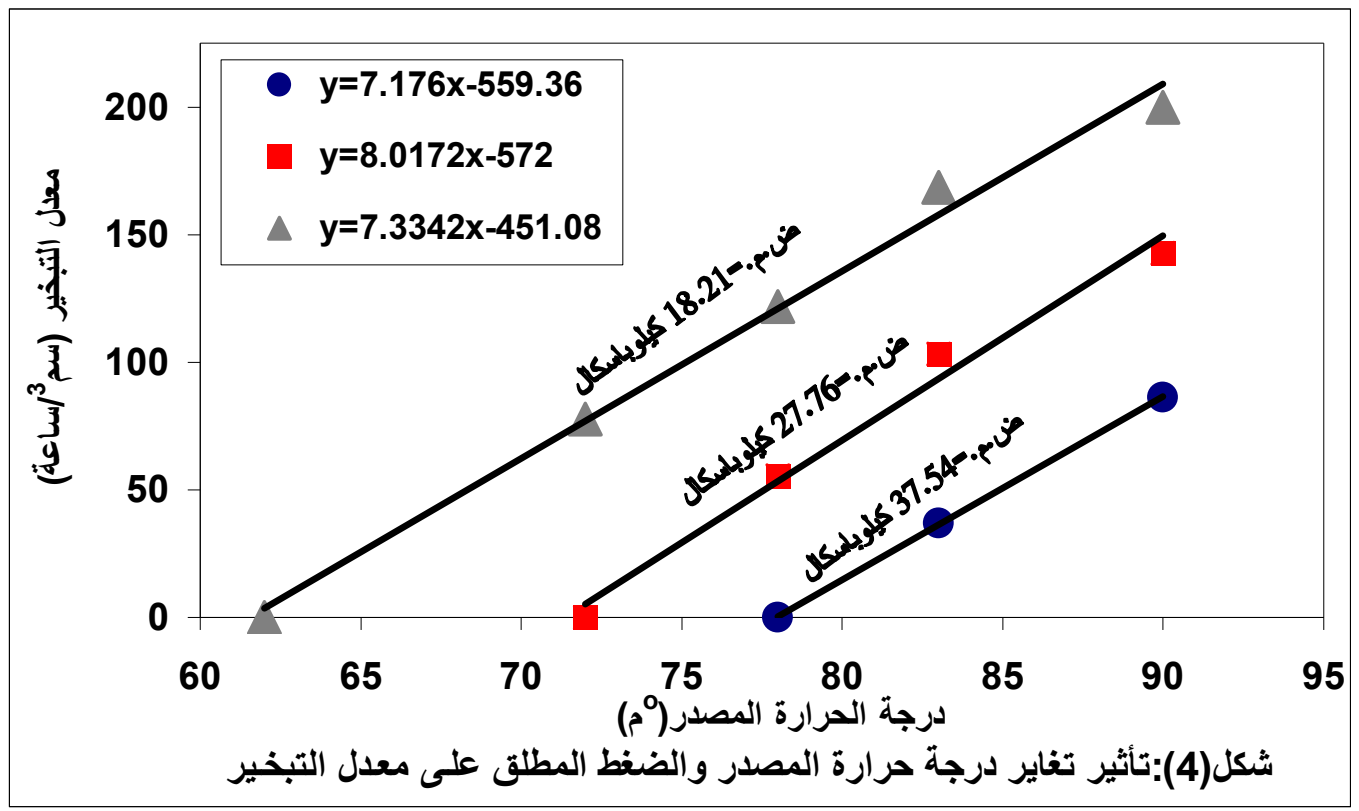

إن التباينات التي حدثت في معدلات التبخير ترتبط بطاقة التبخير [ شكل (5) ] م وهي الطاقة المستهلكة من قبل السائل المتبخر خلال وحدة الزمن إذ تقوم جزيئات السائل قبل تبخر ها بسحب طاقة من جسم السائل الذي تنفصل عنس تمثنل

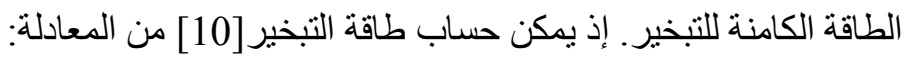

$\mathrm{Qe}=\rho * \mathrm{~h}_{\mathrm{L}} * \mathrm{q}$ 
إذ أن :

Qe

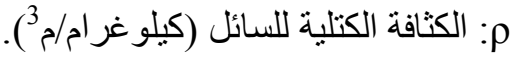

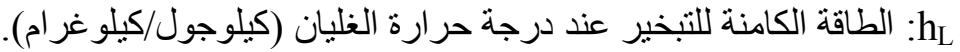
q

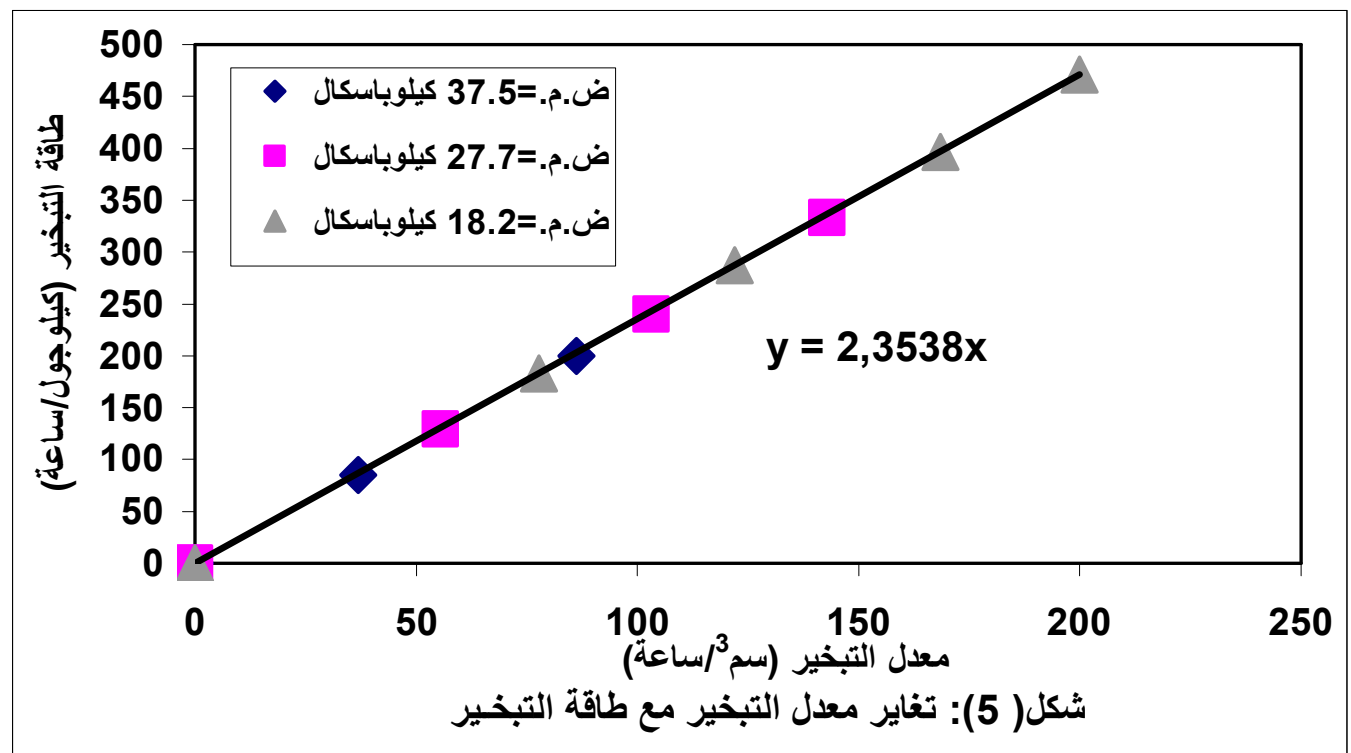

ويلاحظ من الشكل (6) زيادة طاقة التبخير مع زيـادة درجة حرارة المصدر ومـع انخفاض الضغط المطلق عند

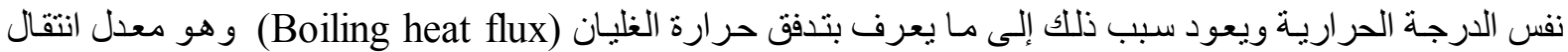

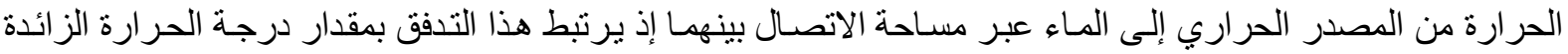

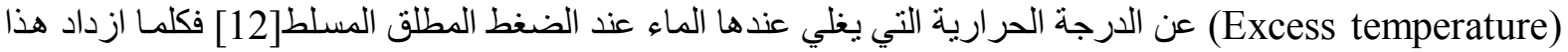

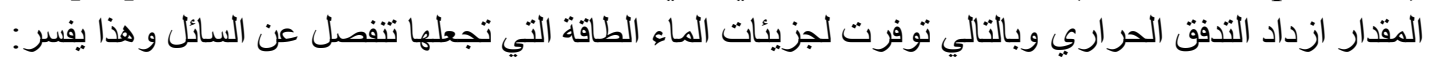

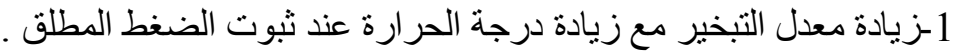

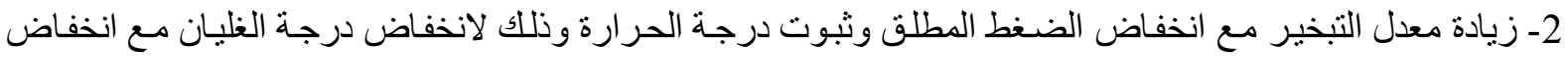

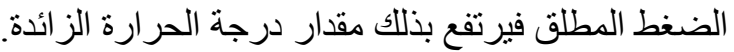
3ـعدم حدوث تبخير يذكر عندما كانت درجة حرارة المصدر مساوية للارجة الحرارية التي بدأ عندها الماء بالغليان نتيجة لعدم حدوث التدفق الحراري.

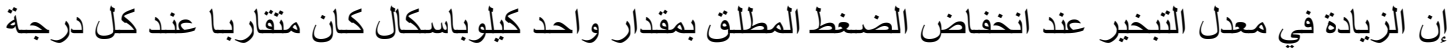

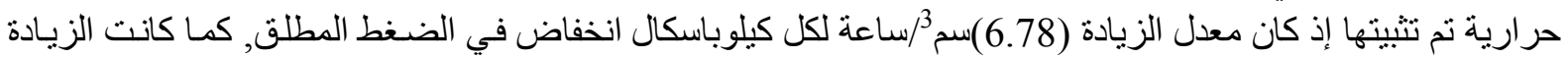

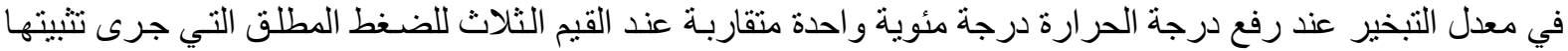

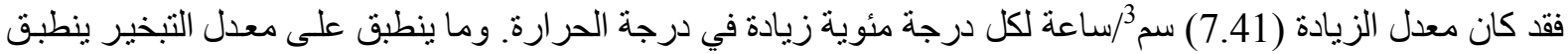

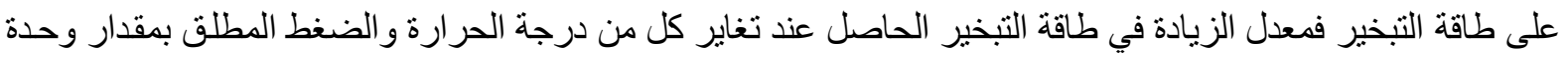

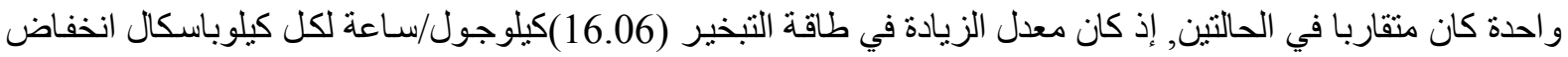

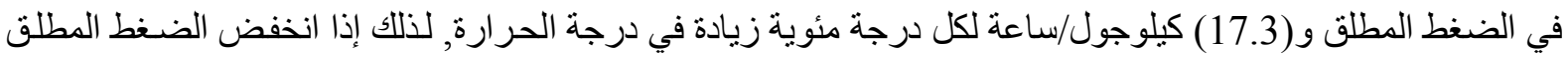

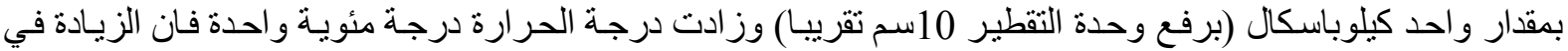

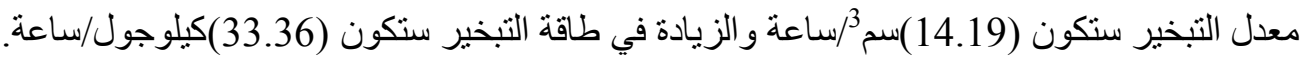




\section{ألعناز: أستخدام ضغط التفريغ في معالجة المياه المالحة}

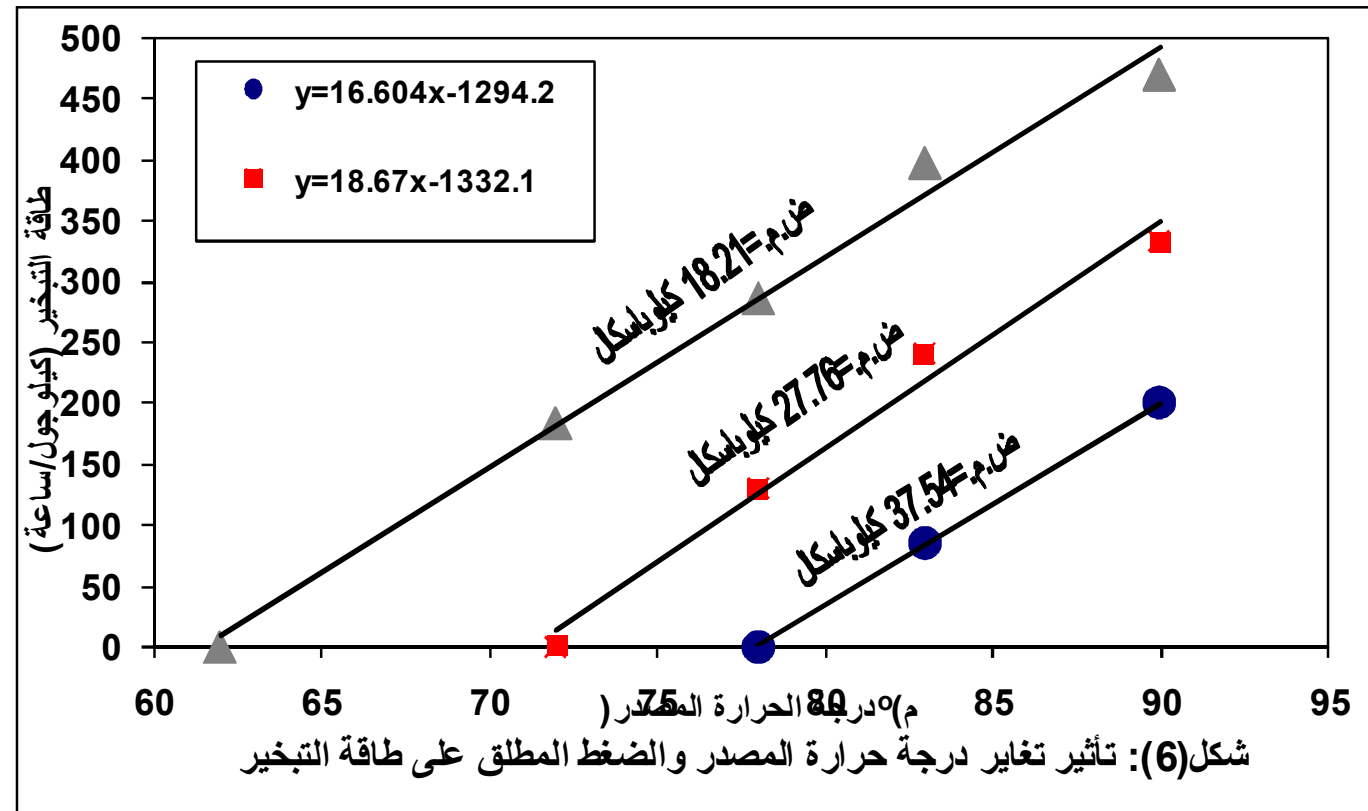

ومما تجدر الإشارة إليه انه عند تطبيق عملية التقطير فانه من الضروري تحديد مقدار التبخير الذي سوف يحصل

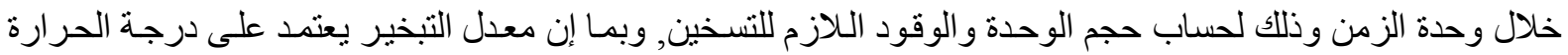

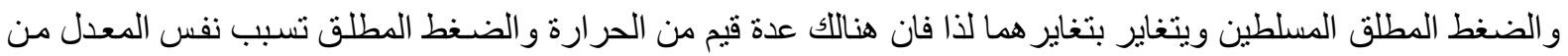

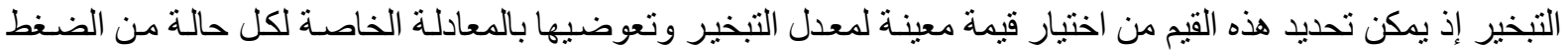

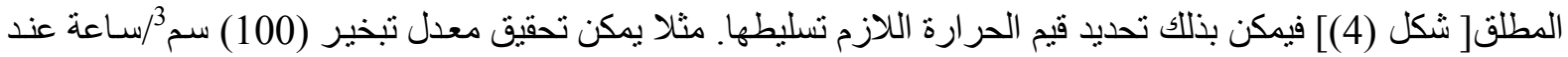

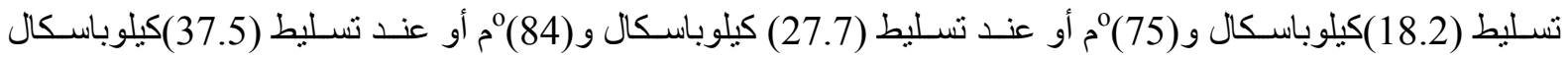

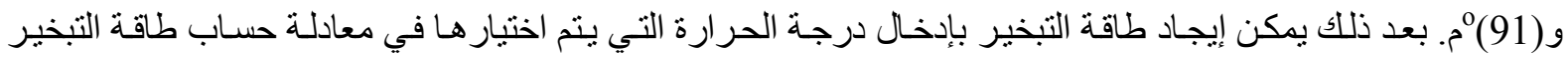

الخاصة بالضغط المطلق[ شكل (6)] أو تعويض معدل التبخير في المعادلة التي تربطه مع طاقة التبخير [نكل (5)].

وبالنسبة لأنبوبة التكثيف فقد جرى تصميمها اعتمادا على مبدأ تسريب الحرارة من المكثف إلى الهواء الجوي

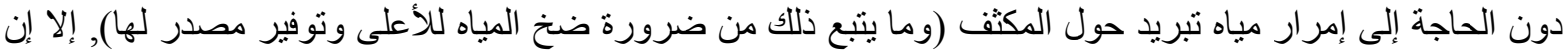

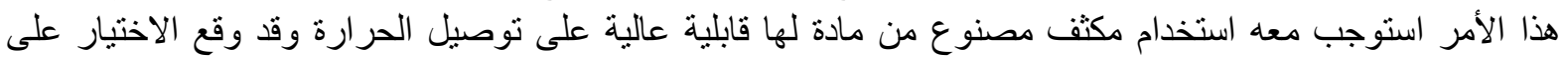

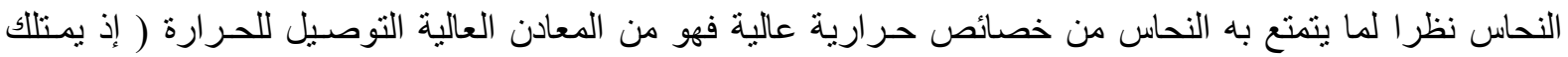
أعلى نوصيل حراري

(Thermal conductivity)

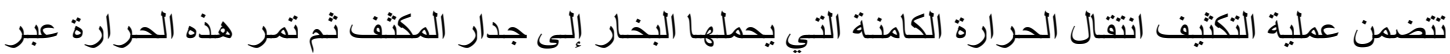

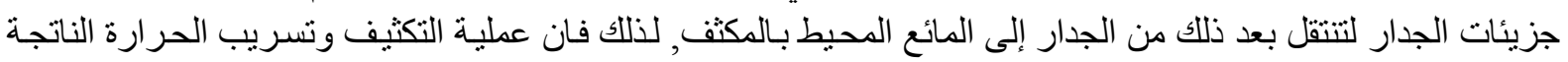

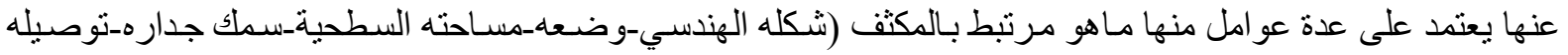

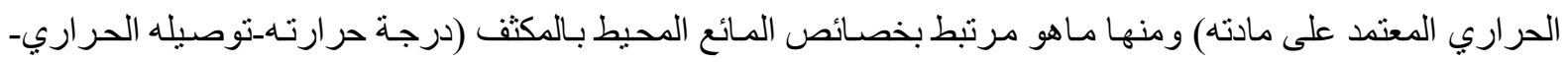

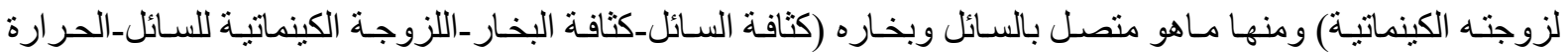

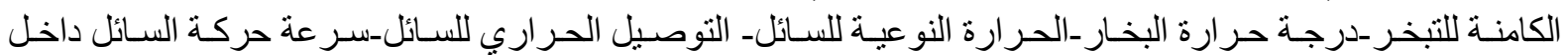

إن هنالك مجموعة من القو انين[12] تضم الخصائص المذكورة وتستخدم لحساب معدل الحرارة المنتقلة بفعل التكثيف

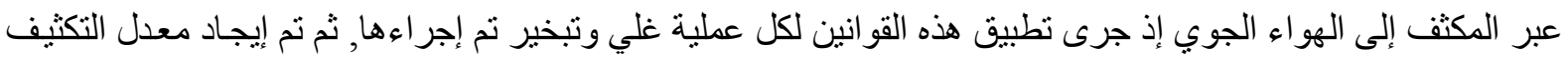

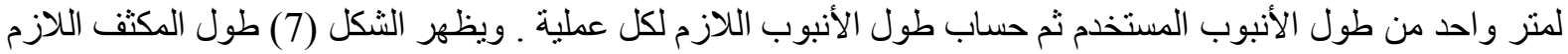

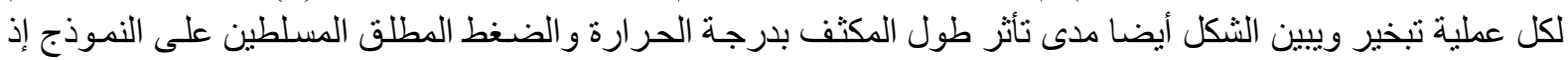
يلاحظ زيادة طول المكثف مع ارتفاع درجة الحر ارة وكذلك مع انخفاض الضغط المطلق إذ يرتبط ذلك وكما تمت الإشـارة 


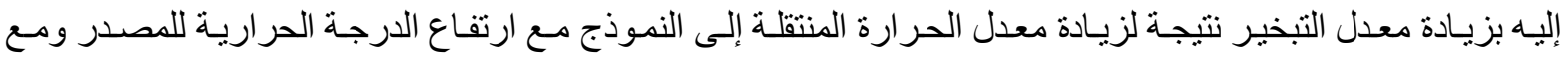

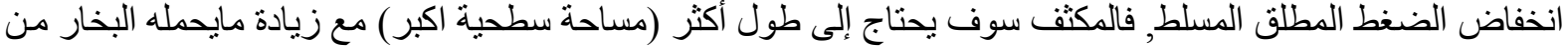
حر ارة كامنة من اللازم تبديدها.

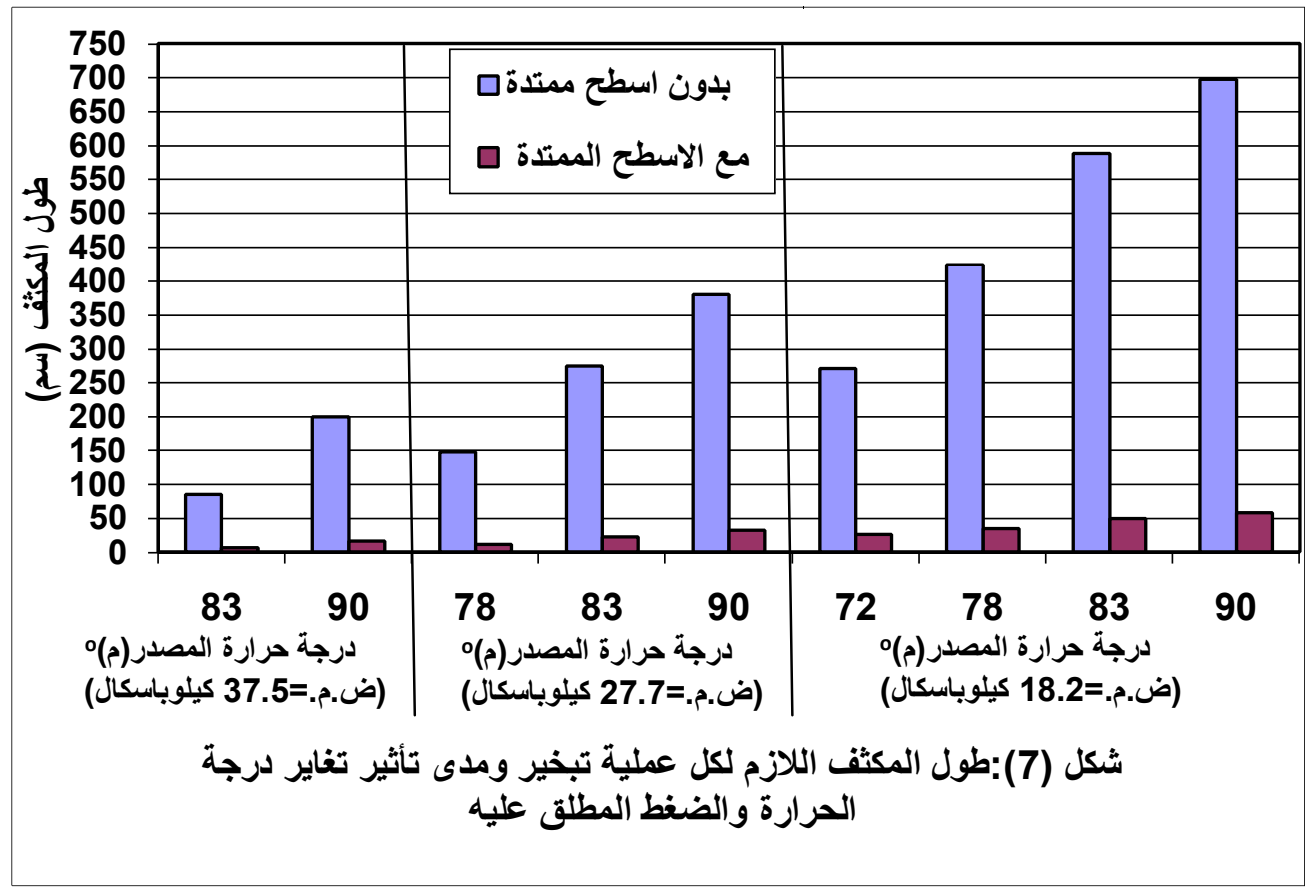

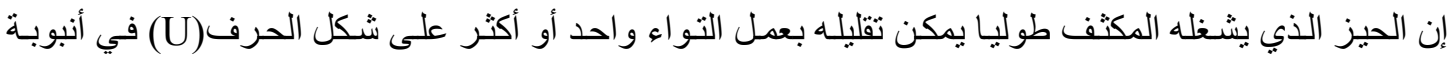

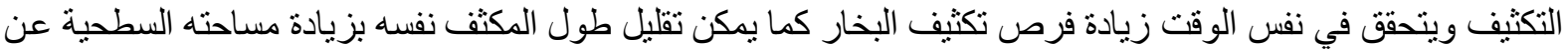

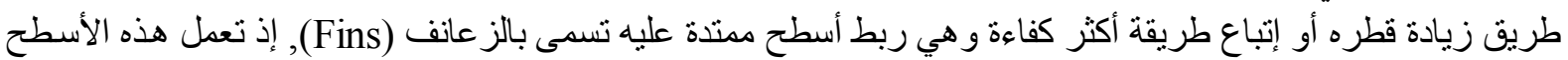

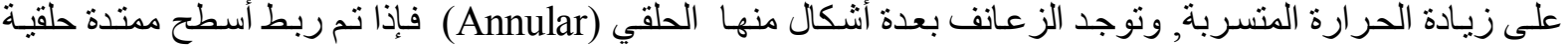
بقطر (94.25)ملم حول المكثف تفصل بين الواحدة والأخرى مسافة (20)ملم فان طول المكثف سوف يكوة يكون بطول اقل بكثير وهو مايظهر من الثكل (7).

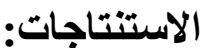

1-يمكن معالجة المياه المالحة بالتقطير في درجات حرارية اقل من (100) م وذلك بتوليد ضغط تفريغ عليها عن طريق

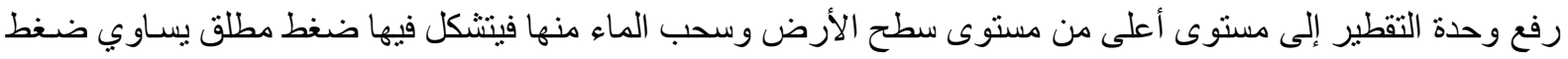
بخار الماء عند تللك الدرجات الحراء الفية

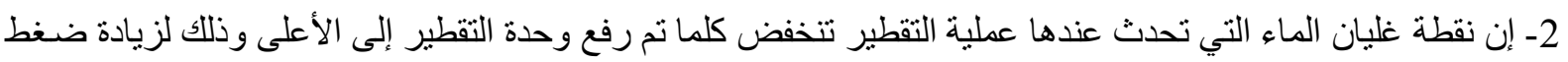
التفريغ المتولد وبالتالي انخفاض الضغط التفاء المطلق المسلط على الماء.

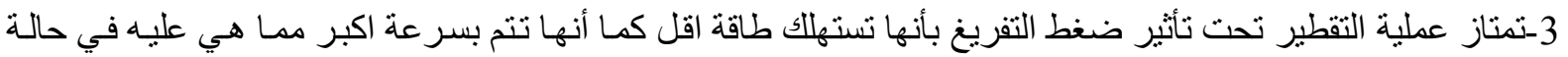

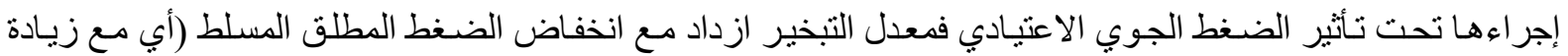

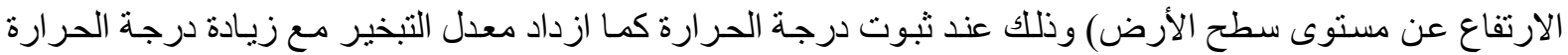

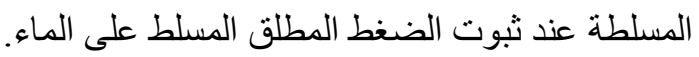

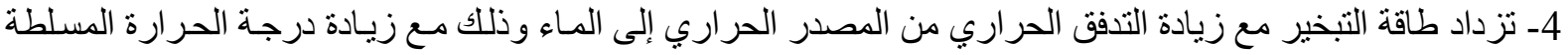

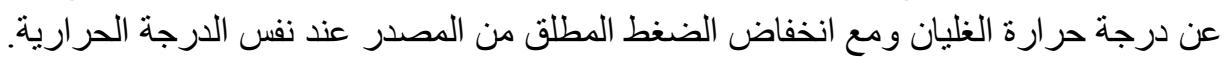

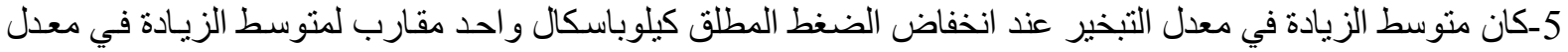
التبخير عند زيادة الحرارة درجة مئوية واحدة, وينطبق ذلك أيضا على طاقة التبخير. 


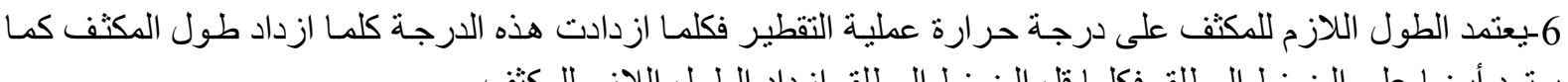
يعتمد أيضا على الضغط المطلق فكلما قل الضغط المطلق ازداد الطول الطول اللازم للمكثف.

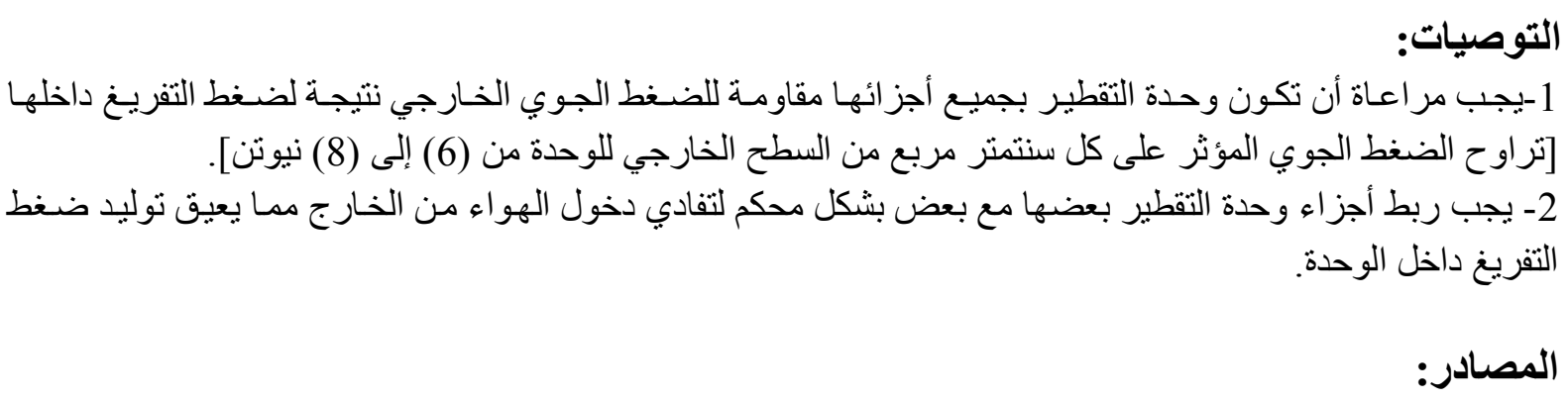

1-Francesca Macedonio, Efrem Curcio and Enrico Drioli, "Integrated membrane systems for seawater desalination: energetic and exergetic analysis economic evaluation experimental study", Desalination, vol. 203, Issues 1-3, February 2007.

2-Ioannis C. Karagiannis and Petros G. Soldatos, "Water desalination cost literature: review and assessment", Desalination, vol. 223, Issues 1-3, March 2008.

3-Nicos X. Tsiourtis, "Desalination and the environment", Desalination, vol. 141, Issue 3, December 2001.

4-Akili D. Khawaji, Ibrahim K. Kutubkhanah and Jong-Mihn Wie, "Advances in seawater desalination Technologies”, Desalination, vol. 221, Issues 1-3, March 2008.

5-Mark J. Hammer and Mark J. Hammer Jr., "Water and Wastewater Technology", $5^{\text {th }}$ ed., Prentice-Hall Inc., New Jersey, 2004.

6-Gilbert M. Masters, "Introduction To Environmental Engineering and Science", $2^{\text {nd }}$ ed., Prentice-Hall Inc., New Jersey, 1998.

7-Stanley E. Manahan, "Environmental Science and Technology”, CRC Press LLC, Florida, 1997.

8-John K. Vennard and Robert L. Street, "Elementary Fluid Mechanics", $6^{\text {th }}$ ed., John Wiley \& Sons, New York, 1982.

9-Yunus A. Cengel and John M. Clmbada, "Fluid Mechanics: Fundamentals and Applications", Mc-Graw Hill, New York, 2006.

10-S. Al-Kharabsheh and D. Yogi Goswami, "Theoretical Analysis of a Water Desalination System Using Low Grade Solar Heat", Journal of Solar Energy Engineering, vol. 126, May, 2004.

11-A. K. Lalzad, I. W. Eames, G. G. Maidment and Karayiannis, "Investigation of a novel small-scale solar desalination plant", International Journal of Low Carbon Technology, April, 2006.

12-Yunus A. Cengel, "Heat Transfer: A practical Approach", $2^{\text {nd }}$ ed., ., Mc-Graw Hill, New York, 2003.

13-James R. Welty, Charles E. Wicks, Robert E. Wilson and Gregory Rorrer, "Fundamentals of Momentum, Heat and Mass Transfer", $4^{\text {th }}$ ed., John Wiley \& Sons, 2001.

14-Lindon C. Tomas, "Fundamentals of Heat transfer", Prentice-Hall, New Jersey, 1980.

$$
\text { تم اجراء البحث في كلية ألهندسة = جامعة ألموصل }
$$

